\title{
Continuous positive airway pressure use: how much is enough?
}

\author{
S. Justin Thomas ${ }^{1,2} \cdot$ David Calhoun $^{3}$
}

Received: 14 September 2021 / Revised: 16 September 2021 / Accepted: 23 September 2021 / Published online: 24 December 2021

(C) The Japanese Society of Hypertension 2021

Obstructive sleep apnea (OSA) is associated with prevalent and incident hypertension, as well as antihypertensive treatment resistance [1-4]. While OSA is associated with higher levels of daytime blood pressure (BP), nighttime or asleep BP may be even more impacted by OSA-related sequelae [5-7]. In fact, one study reported BP surges as high as systolic BP/diastolic BP of $240 / 130 \mathrm{mmHg}$ associated with apneic events [5]. OSA-related increases in BP are attributable to both hypoxemia and arousal-related sympathetic nervous system activation [6,7]. Therefore, continuous positive airway pressure (CPAP), which is the gold standard treatment for OSA, should also reduce daytime and nighttime BP and the risk for hypertension. However, a systematic review and meta-analysis examining the impact of CPAP use on BP reported disparate effects [8]. Overall, the authors reported a statistically significant but low to moderate effect of CPAP on BP.

The study by Sapina-Beltran et al. sought to determine the effects of CPAP on ambulatory BP among 89 patients with resistant hypertension, an apnea/hypopnea index $(\mathrm{AHI}) \geq$ 15 events per hour (moderate to severe OSA), and who had been using CPAP for 1 year. The authors reported that resistant hypertensive patients with nocturnal normotension did not exhibit significant changes in ambulatory BP in response to CPAP, while resistant hypertensive patients with nocturnal hypertension had a reduction in mean nighttime BP of 4.4 mmHg (95\% confidence interval: $-7.1,-1.7)$. This study also reported no differences in ambulatory BP based on the BP dipping pattern (i.e., dipping versus nondipping BP).

S. Justin Thomas

sjthoma@uabmc.edu

1 Department of Psychiatry, University of Alabama at Birmingham, Birmingham, AL, USA

2 Sleep/Wake Disorders Center, University of Alabama at Birmingham, Birmingham, AL, USA

3 Sentara Martha Jefferson Hospital, Sleep Medicine, Charlottesville, VA, USA
As Sapina-Beltran et al. point out, one potential explanation for the inconsistent findings and low effect size of the effect of CPAP on BP in their study, as well as others, may lie in the definition and inclusion of adequate CPAP adherence, which is typically set at a mean of $4 \mathrm{~h}$ of use per day, consistent with the US Center for Medicare and Medicaid Services definition of adherence (i.e., $\geq 4 \mathrm{~h}$ of CPAP use on $70 \%$ of nights in a consecutive 30-day period in the first 90 days of treatment). However, $4 \mathrm{~h}$ of CPAP use may be insufficient to adequately treat OSA and produce physiological effects, particularly for patients who have OSA predominantly during REM sleep. To illustrate this point, we present a sleep hypnogram in which REM periods cycle approximately every $90 \mathrm{~min}$ during the sleep period and become longer as the night progresses (Fig. 1). If a patient uses CPAP during the first half of the night for 4 hours but removes it midway through the sleep period, they would be considered adequately adherent and included in most of the clinical trials studying the effects of CPAP [8]. However, the majority of the apneic events would remain untreated in this particular example, making any conclusion on the effects of CPAP tenuous. By comparison, the cutoff for good adherence to the antihypertensive medication regimen is generally $\geq 80 \%$ [9], which would translate to a minimum of $6.4 \mathrm{~h}$ of CPAP use in an 8-hour sleep period. Use of CPAP for $6.5 \mathrm{~h}$ in the hypnogram as originally depicted would likely encompass an additional REM period, more adequately treat OSA, and result in a lower AHI (Fig. 2).

CPAP adherence is generally low, and studies have suggested that $>6 \mathrm{~h}$ of use is necessary to reverse many of the effects of OSA [10]. In the aforementioned meta-analysis on the effect of CPAP on BP, only 4 of the 30 studies (13.3\%) reported a mean of 6 or more hours of CPAP use, with a maximum adherence of $6.4 \mathrm{~h}$ [8]. Thus, it may be time to reconsider the definition of adequate CPAP use in clinical research while urging caution in interpreting the impact of CPAP on health outcomes. Any lack of impact of CPAP may not necessarily mean that CPAP use does not convey benefit but instead indicates that patients simply are not using CPAP long enough to realize this benefit. 
Fig. 1 Use of continuous positive airway pressure (CPAP) for $4 \mathrm{~h}$ in the context of a hypnogram
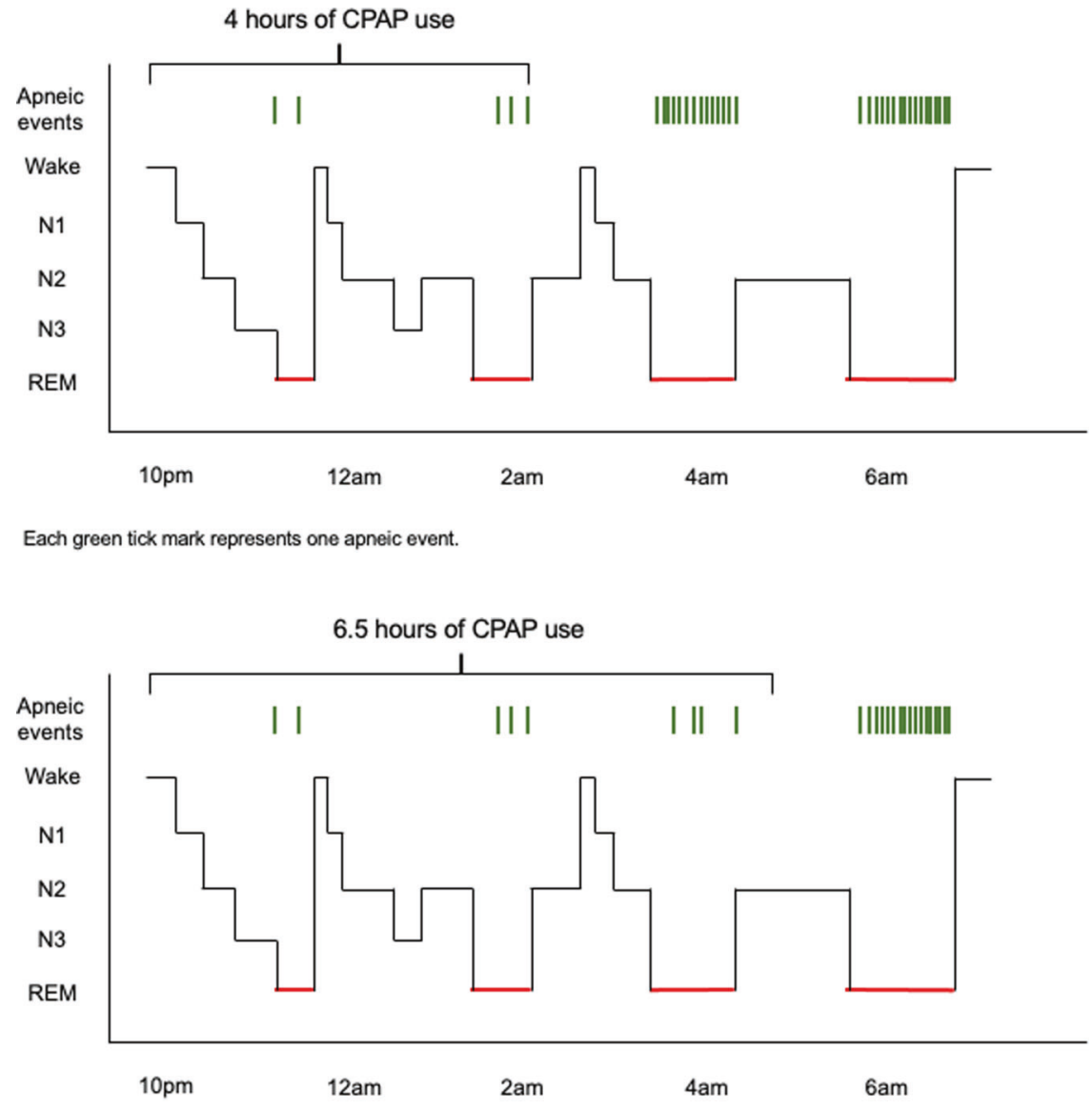

Each green tick mark represents one apneic event.
Fig. 2 Use of continuous positive airway pressure (CPAP) for $6.5 \mathrm{~h}$ in the context of a hypnogram
4. Goncalves SC, Martinez D, Gus M, de Abreu-Silva EO, Bertoluci C, Dutra I, et al. Obstructive sleep apnea and resistant hypertension: a case-control study. Chest. 2007;132:1858-62.

Conflict of interest The authors declare no competing interests.

Publisher's note Springer Nature remains neutral with regard to jurisdictional claims in published maps and institutional affiliations.

\section{References}

1. Peppard PE, Young T, Palta M, Skatrud J. Prospective study of the association between sleep-disordered breathing and hypertension. N Engl J Med. 2000;342:1378-84.

2. Nieto FJ, Young TB, Lind BK, Shahar E, Samet JM, Redline S, et al. Association of sleep-disordered breathing, sleep apnea, and hypertension in a large community-based study. Sleep Heart Health Study. JAMA. 2000;283:1829-36.

3. Walia HK, Li H, Rueschman M, Bhatt DL, Patel SR, Quan SF, et al. Association of severe obstructive sleep apnea and elevated blood pressure despite antihypertensive medication use. J Clin Sleep Med. 2014;10:835-43.
5. Somers VK, Dyken ME, Clary MP, Abboud FM. Sympathetic neural mechanisms in obstructive sleep apnea. J Clin Invest. 1995; 96:1897-904.

6. Phillips C, Hedner J, Berend N, Grunstein R. Diurnal and obstructive sleep apnea influences on arterial stiffness and central blood pressure in men. Sleep. 2005;28:604-9.

7. Phillips CL, Yang Q, Williams A, Roth M, Yee BJ, Hedner JA, et al. The effect of short-term withdrawal from continuous positive airway pressure therapy on sympathetic activity and markers of vascular inflammation in subjects with obstructive sleep apnoea. J Sleep Res. 2007;16:217-25.

8. Fava C, Dorigoni S, Dalle Vedove F, Danese E, Montagnana M, Guidi GC, et al. Effect of CPAP on blood pressure in patients with OSA/hypopnea a systematic review and meta-analysis. Chest. 2014;145:762-71.

9. Burnier M, Egan BM. Adherence in hypertension. Circ Res. 2019; 124:1124-40.

10. Weaver TE, Grunstein RR. Adherence to continuous positive airway pressure therapy: the challenge to effective treatment. Proc Am Thorac Soc. 2008;5:173-8. 